ist ein echtes Leichenklagelied, das die hebräischen Weiber jener Zeit zu singen pflegten.

Mancherlei habe ich berühren und versuchsweise entscheiden müssen, worüber man verschiedener Meinung bleiben wird. Dafs aber das Stück ein Klagelied sein soll und nur als solches seine Wirkung getban hat, wird man anerkennen müssen. Neben Jer. 9, $16 \mathrm{ff}$. bildet es die stärkste Stütze für das Ergebnifs meiner mehrfach erwähnten Abhandlung, dafs der in so vielen Stücken nachgewiesene, eigenthümlich gebaute Vers dem althebräischen Leichenklageliede als solchem und regelmäfsig eignete.

\title{
Nachträgliches zu Jahrgang I, S. 117.
}

Aus einem Briefe Ed. Meyer's an den Herausgeber.

Schon lange habe ich, wie Sie wissen, die Absicht, einige Nachträge zu meinem Aufsatz Z. altt. W. I, $117 \mathrm{ff}$. zu geben. Namentlich die Bemerkungen über die ägyptischen Angaben S. 127 bedürfen einiger Ausführungen und Berichtigungen, die sich mir bei gründlicher Durcharbeitung des einschlägigen Materials ergeben haben. Die Resultate derselben sind in meiner demnächst erscheinenden Geschichte des Alterthums I, \& 180 und sonst enthalten; zu einer ausführlicheren Bearbeitung der ägyptischen Angaben über die Geographie Syriens und Palästina's, die ich längst plane, finde ich aber noch immer nicht die Zeit. Da Sie mich nun wieder an meine Absicht gemahnt haben, so will ich wenigstens die wichtigsten Bemerkungen kurz zusammenstellen und bitte Sie, vorläufig damit vorlicb zu nehmen.

Den Namen Amar, oder, wie wohl richtiger zu schreiben ist, Amur, = אמרי , habe ich S. 127 zu weit gefarst. Wie alle meine Vorgänger hatte ich das bekannte Tableau, 
welches den Angriff Seti I auf die Stadt Qadeš en pa Amur „im Amurlande“ darstellt (Rosellini mon. stor. 53), auf die im Orontes gelegene Chetahauptstadt dieses Namens bezogen. Ein Blick auf die Abbildung genügt in dessen, um dies als Irrthum nachzuweisen: das Qadeš Seti I liegt auf einem bewaldeten Berge, die von Ramses II oft abgebildete Chetahauptstadt dagegen auf einer Insel im Flusse. Mithin sind beide verschieden, und daher erklärt sich bei Seti der Zusatz „im Lande Amur“. Er soll die Bergstadt Qadeš im Amoriterlande von der Stadt der Cheta unterscheiden. Erstere ist mithin zweifellos das hebräische Qadeš in Naphtali. Ob Dhutmes III in seiner bekannten Städteliste denselben Ort oder die Chetastadt meint, ist mit Sicherheit nicht zu entscheiden.

Demnach ist die Behauptung zu streichen, dafs die Cheta bei den Aegyptern zum Amoriterlande gerechnet würden. Letzteres ist vielmehr bei ihnen immer Palästina, und zwar, wie es scheint, namentlich Nordpalästina, in völliger Uebereinstimmung mit dem alttest. Sprachgebrauch.

Im Uebrigen gliedern sich die ägyptischen Namen folgendermafsen : Nördlich von den Šasu, den Beduinen der Sinai-Halbinsel, folgt das Land und Volk Oberrutenu ( $\mathrm{Ru}$ tenu hert), das im Wesentlichen unserem Palästina entspricht. Im Gegensatz dazu wird das syrische Tiefland gelegentlich als Unterrutenu (Rutenu chert) bezeichnet. Das phönikische Küstenland heifst, wie längst bekannt ist, Kaftu, seine Bewohner Fenchu d.i. Фoivıxes. In Coelesyrien am Orontes wohnen die Cheta. An sie schliefsen sich im Norden zahlreiche kleine Districte, vor allem aber das Land Naharain (geschrieben Nhrina), d. h. ארם נהרים. Der ägyptische Name bezeichnet eben so wenig wie der entsprechende hebräische jemals Mesopotamien, sondern immer 
das Gebiet zu beiden Seiten des Euphrat, mit den Städten Karkamǐ̌, Bambyke, Nii u. a. Die Form ist nichts weniger als ein Dual, sondern eine der häufigen localen Bildungen auf -aim, wie מצרים, ירשלים, מחנים, , מפרים, und bedeutet „Stromland." - Als Name für die Bevölkerung Syriens oder speciell die Kanaans findet sich sehr häufig Charu verwandt. Aufserdem werden alle syrischen Lande zusammengefafst unter dem Namen Șahi (oder Zahi?).

Auch die Stellen über Kana'an (geschrieben Kan'na) sind etwas anders aufzufassen, als S. 127 geschehen ist. Ich hatte mich, wie ich bei Vergleichung des mir 1881 unzugänglichen grofsen Harrispapyrus (pl. 9, 1-3) sehe, mit Unrecht einfach an Brugs c h' Gessch. Aegyptens 460 angeschlossen. Die Stelle des Papyrus lautet : „Ich (Ramses III) habe dir [dem Amon] ein Heiligthum erbaut im Lande Zah (Syrien) [so grofs] wie der Horizont des Himmels oben, das „Haus Ramses III em pa Kana'an“.... . es kommen die Völker von Rutenu zu ihm mit ihren Gaben." Demnach ist hier keineswegs von einer Stadt oder Festung Kana'an die Rede, sondern der von Ramses III erbaute Tempel liegt em pa Kana'an „in dem [Lande] Kana'an." Dementsprechend sind auch die Angaben Seti I bei L e psi u s Denkm. III, 126 a aufzufassen. Der König zieht gegen die Šasu, d. i. die Beduinen der Sinai-Halbinsel, „von der Feste von Șaru (Tanis) er pa Kana'an bis zum [Lande] Kanaran." In dem beigegebenen Tableau ist der Kampf abgebildet und im Hintergrunde eine im Gebirge liegende Festung mit der Beischrift dma en pa Kana'an „die Feste des [Landes] Kana'an." Pa Kana'an „das Land Kana'an" bezeichnet somit bei den Aegyptern Südpalästina. Hängt

*) Auch أين , אין, ist vielleicht hierzu zu stellen. 
damit zusammen, dafs die jüdischen Schriftsteller כנעני, die ephraimitischen אמרי sagen?

Sonst noch ein paar Berichtigungen. S. 119 Z. 5 lies Jahwe für Mose. S. 125 ist zu den Stellen, an denen die 7 Völker vorkommen, Reg. I, 9, 20 nachzutragen. S. 127 ist Z. $21-23$ zu streichen; ich habe die arge Flüchtigkeit begangen, die (sonst unbekannte) Stadt Laodikea, deren Lage die Ruinen von Umm el 'Awâmîd (zwischen Tyrus und Akko am Meere) bezeichnen, mit Laodikea am Libanon zu verwechseln. S. 133 Z. 23 Bamot oder Bamot Ba'al ist doch wohl das Bêt Bamot der Meša inschrift Z. 27. S. 135,6 streiche „Jos. 19,47 aus Jud. 18." S. 140 Anm. 3 ist Amos 2, 10 zu 5, 25 hinzuzufügen.

Bei meiner Reconstruction des Liedes Num. 21, $27 \mathrm{ff}$. nach LXX haben Sie in v. ונשים עוד נפחו איש על מירבא 30

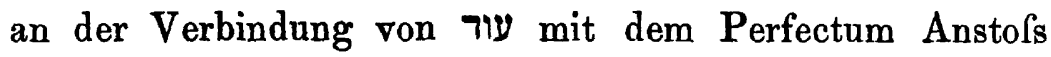
genommen. Eine vollständige Parallele scheint mir in der vielumstrittenen Stelle der Ešmun'azarinschrift Z. 18 vorzuliegen : וער יתן לן ארן מלכם אית דאר ויפי, die doch kaum anders übersëtzt werden kann als „und aufserdem gab uns der Grofskönig Dor und Joppe.“

Leipzig, den 11. Juni 1883.

Eduard Meyer. 